\title{
Process Design and Material Development for High-Temperature Applications
}

\author{
CHAI REN (i) ${ }^{1,3}$ and RAVI K. ENNETI ${ }^{2}$ \\ 1.-Xiamen Tungsten Co. Ltd, Chengdu, China. 2.-Global Tungsten and \\ Powders, Towanda, PA, USA. 3.—e-mail: chai.ren.cn@gmail.com
}

Due to their high melting points, refractory metals and materials are excellent candidates for use in many high-temperature applications such as heating elements, insulation screens, propulsion systems, and plasma-facing components. They are also widely used as additives or substituents in other material systems to improve their functional or structural performance at elevated temperature. However, as most refractory materials share common drawbacks such as room-temperature brittleness, sophisticated material designs and systematic analyses are always highly valued.

Besides material studies, the development of processing technologies shares the same level of importance. Fabricating parts from refractory metals and materials is generally difficult due to their high melting point and low ductility. Powder metallurgy and thermomechanical processes are some of the choices available for industrial-scale production of parts from refractory metals. Recent progress in advanced processing methods such as additive manufacturing may lead to enhanced material performance or increased production efficiency. Studies on improving conventional technologies or the development of novel processing approaches are essential.

This 2020 special topic on refractory metals and materials focuses on the latest experimental and theoretical advances related to refractory materials for use in high-temperature applications. The papers are mostly devoted to the challenges in producing these materials in an innovative way with optimized functionality. Contributions include carbothermal reduction to form carbides, increasing

Chai Ren and Ravi K. Enneti are Guest Editors for the Refractory Metals and Materials Committee of TMS and coordinated the topic Process Design and Material Development for High-Temperature Applications in this issue.

(Received September 8, 2020; accepted September 9, 2020; published online September 30, 2020) the decomposition temperature using additives, refractory addition, and process control to enhance high-temperature and mechanical properties.

Molybdenum carbide shows an excellent combination of good wear resistance, low reactivity, and high melting point, making it a widely used coating and reinforcement material for application in hightemperature environment. It is also used in catalysis and energy storage applications due to its unique electronic properties. In "Desulfurizer-enhanced carbothermal reduction of $\mathrm{MoS}_{2}$ to synthesize $\mathrm{Mo}_{2} \mathrm{C}$," Chang et al. discuss a novel approach to synthesize $\mathrm{Mo}_{2} \mathrm{C}$ by carbothermal reduction with $\mathrm{Na}_{2} \mathrm{CO}_{3}, \mathrm{CaO}$, and $\mathrm{Fe}_{2} \mathrm{O}_{3}$ as desulfurizer. By addition of desulfurizer, this process shows clear advantages, as it decreases the reaction temperature over $350^{\circ} \mathrm{C}$, eliminates the emission of sulfurous gas with potential environmental concerns, and separates the byproduct $\mathrm{Na}_{2} \mathrm{~S}$ using a simple water leaching process.

Due to its high temperature stability, low thermal conductivity, and good corrosion resistance, zircon is a typical material used in high-temperature applications in the iron and steel industries. As it directly determines the lifetime of zircon, its decomposition temperature is one of the most extensively studied characteristics in this area. In "Comparison of $\mathrm{MnO}_{2}$ and $\mathrm{ZnO}$ additives on zircon decomposition and formation of solid solution," Majidian et al. study the effects of $\mathrm{MnO}_{2}$ and $\mathrm{ZnO}$ additives on the decomposition behavior of zircon. It is reported that both $\mathrm{ZnO}$ and $\mathrm{MnO}_{2}$ additives form secondary phases with zircon, inhibiting grain growth and improving the high-temperature performance. The maximum decomposition temperature achieved through this method is $1650^{\circ} \mathrm{C}$ with addition of over 1 wt.\% $\mathrm{ZnO}$.

$\mathrm{CoW}$ is a recently developed superalloy system for improving jet engine efficiency. Thanks to the alloying with $\mathrm{W}, \mathrm{CoW}$ alloy shows promising potential for high-temperature applications above $750^{\circ} \mathrm{C}$ and has been proposed as a future replacement for 
Ni-based superalloy. In "Effect of cooling rate on the precipitation behaviour of gamma prime in a newlydeveloped Co-based superalloy," Abedi et al. report that the precipitation rate of gamma prime phase increases while the maximum precipitation rate point decreases as a function of cooling rate. The average size and shape of gamma prime precipitates also change as the cooling rate increases. Overall, this CoW alloy shows considerably higher activation energy for precipitation than Ni-based superalloy, which may be beneficial for many high-temperature applications.

WC is a conventional refractory material which has been extensively used in cutting tools and hightemperature structural applications. It is also used as an additive in many materials to improve their hardness, wear resistance, or high-temperature performance. In " $\mathrm{Al}_{2} \mathrm{O}_{3} / \mathrm{TiO}_{2}$-Ni-WC composite coatings designed for enhanced wear performance by laser cladding under high-frequency micro-vibration," Wang et al. study the effect of WC addition on the mechanical behavior of traditional $\mathrm{Al}_{2} \mathrm{O}_{3}-\mathrm{TiO}_{2}$ composite coating. With increasing WC content, the microhardness, coefficient of friction, and wear resistance of this coating material increase, reaching the optimized point at $20 \% \mathrm{WC}$. This behavior is achieved through the high hardness and wear resistance of WC particles, as well as the strong bonding strength by the formation of $\mathrm{NiTi}$ intermetallic compounds.

The papers in this special topic on Process Design and Material Development for High-Temperature Applications can be accessed via the Table of Contents page of the November issue at https://link.sp ringer.com/journal/11837/72/11/page/1.

\section{CONFLICT OF INTEREST}

On behalf of all the authors, the corresponding author states that there is no conflict of interest.

Publisher's Note Springer Nature remains neutral with regard to jurisdictional claims in published maps and institutional affiliations. 